\title{
X-linked intellectual disability-short stature-overweight syndrome
}

INSERM

\section{Source}

INSERM. (1999). Orphanet: an online rare disease and orphan drug data base. X-linked intellectual disability-short stature-overweight syndrome. ORPHA:457240

X-linked intellectual disability-short stature-overweight syndrome is a multiple congenital anomalies syndrome characterized by borderline to severe intellectual disability, speech delay, short stature, elevated body mass index, a pattern of truncal obesity (reported in older males), and variable neurologic features (e.g. hypotonia, tremors, gait disturbances, behavioral problems, and seizure disorders). Less common manifestations include microcephaly, microorchidism and/or microphallus. Dysmorphic features have been reported in some patients but no consitent pattern has been noted. 